\title{
Age-related Differences in Processing Speed in Preschool Children
}

\author{
Sergey Kiselev*
}

Department of Clinical Psychology and Psychophysiology, Ural Federal University named after the first President of Russia B.N. Yeltsin, Ekaterinburg, Russia

\begin{abstract}
The aim of this study was to assess whether age-related differences in reaction time can be explained satisfactorily in terms of a global age-related differences in processing speed alone. We investigated the age-related differences in simple, discrimination and choice reaction time in 4- to 6-year-old children and young adults using approach proposed by Madden et al. and Ridderinkhoff \& van der Molen. This research demonstrates that there are clear age-related differences in processing speed not only between young children and adults but also between three age groups of young children. The use of the regression approach in this study provides further support for the presence of the global age-related differences in processing speed both between young children and adults and between young children of three age groups. The current data also confirmed the results of previous researches that the magnitude of the slowing coefficient decreases with increasing age. However, using transformation method proposed by Madden et al. and Ridderinkhoff \& van der Molen we revealed that there are not only global age-related differences but also process-specific age-related differences in processing speed. We assume that the age-related differences in processing speed can be understood in relation to the heterochronicity of child brain development.
\end{abstract}

Keywords: Processing speed, preschool children, reaction time, heterochronicity, developmental psychology.

\section{INTRODUCTION}

Age-related differences in the processing speed has been observed in a great variety of tasks involving visual search, letter discrimination, memory search, name retrieval, mental addition, mental rotation, and response selection [1-3]. In spite of the great amount of researches in this area, we know relatively little about the nature of this developmental tendency.

There is well-developed idea that the age differences in the processing speed are due to some general developmental mechanism $[4,5]$. This possibility has been examined by using a procedure pioneered by Brinley [6] in the study of aging. This technique consists of plotting the RT data of a particular age group against those of young adults either across levels of a task or across tasks varying in complexity. Using this procedure in children has revealed that simple mathematical equations accurately predict the latencies of the child group from the latencies of the young adults [4]. The mean RT in childhood at any specific age ( $\left.R T_{\text {child }}\right)$ can be predicted from young adults' mean RT $\left(R T_{\text {adult }}\right)$ by multiplication of a "slowing" coefficient $\left(m_{\mathrm{age}}\right)$, essentially the slope of a regression function.

$R T_{\text {child }}=m_{\text {age }} R T_{\text {adult }}$

The value of the "slowing" coefficient then can be obtained through simple regression analysis. Almost without

*Address correspondence to this author at the Department of Clinical Psychology and Psychophysiology, Ural State University named after the first President of Russia B.N. Yeltsin, Ekaterinburg, Russia;

E-mail: s.j.kiselev@urfu.ru exception the fit of regression equations is strong, for which nearly all of the variance in the group means is accounted, with $R^{2}$ typically exceeding 0.90 , and often greater than 0.95 [7].

An early example of this approach in the developmental literature is provided by Hale [1]. She investigated 10-, 12-, and 15-year-olds and a group of young adults (19-year-olds) on four reaction time tasks: a choice RT task, a letter matching task, a mental rotation task, and an abstract matching task. For each individual child group, eight mean latencies were regressed against those of the young adult group. For each age group, the linear regression function accounted for more than $98 \%$ of the variance. The unstandardized slope of the regression function was greater than 1.0 for the first two age groups, with an apparent decrement across increasing age groups from 1.82 in 10 year-olds to 1.0 in 15-year-olds and young adults. The regression slope did not differ with respect to task: therefore, Hale [1] concluded that the developmental differences in the processing speed are task independent. That is, the RT of a child at any age or task type can be predicted directly from the RT of a young adult by the linear regression equation.

Miller and Vernon [8] investigated developmental increases in processing speed in 4- to 6-year-old children, relative to adults, using a battery of 8 computer-administered tests. Adult RTs accounted for $90 \%, 93 \%$, and $90 \%$ of the variability of RTs of 4-, 5-, and 6-year-olds, respectively. The slope of regression functions decreased with age group from 3.74 in 4-year-olds to 3.20 in 5-year-olds, and to 2.92 in 6-year-olds, regardless of task type. These results were interpreted as supporting the global developmental trend hypothesis, even in very young children. That is, the 
decrement in RT from 4- to 6-year-olds was considered to be determined by global maturational factor.

Using both supplementary meta-analysis and experimental data, Kail [5] concluded that developmental differences in the processing speed are due to a global mechanism, although the nature of this mechanism remains unclear. Kail speculated that one potential mechanism might relate to the information-loss model that is with increasing age children are better able to inhibit irrelevancy [9]. More specifically, as children mature they are better able to inhibit processing steps that are irrelevant to task performance. The net result is that less information is "lost" in irrelevant stimulus and more information reaches the processing steps that are pertinent to task performance. As more information becomes available to the task-relevant processing steps less time is needed for responding.

In contrast, several authors $[3,10,11]$ demonstrated that regression approach conceals process-specific age-related differences in processing speed. That is, even when local, process-specific developmental differences in performance are present in the data, the results of the regression analysis will yield only a single regression equation, thereby erroneously supporting a global-difference hypothesis.

The limitation of the regression approach has motivated the development of several alternative approaches [12]. In particular, Madden et al. [11] developed a transformation method that allows to use advantages of both a regression analysis and ANOVA. In this method, a Brinley plot is calculated for the task condition means, and then the young adults' RTs are transformed by multiplying them with the parameters of the best-fitting Brinley plot function. The new data set, with transformed RTs for younger adults and untransformed RTs for older adults, are then submitted to ANOVA. Interactions between age group and task condition that remain significant following the transformation can be viewed as representing effects beyond those associated with generalized age-related slowing. In other words, the presence of any interactions after transformation would indicate the presence of task-specific age affects not attributable to global age-related differences in processing speed. Ridderinkhoff \& van der Molen [3] using this transformation method for children in three age groups and adults revealed the interactions between age group and task condition. It was proposed that this transformation method can be effectively used to reveal the task-specific age-related differences in processing speed.

The objective of this study is to assess whether agerelated differences in reaction time can be explained satisfactorily in terms of a global age-related differences in processing speed alone. To this end, we investigated the agerelated differences in simple, discrimination and choice reaction time in 4- to 6-year-old children and young adults using approach proposed by Madden et al. [11] and Ridderinkhoff \& van der Molen [3].

\section{MATERIALS AND METHODOLOGY}

\section{Participants}

A total of 165 Russian-speaking children participated in this study. The sample consisted of 54 4-years-olds $(\mathrm{M}=$ 4.47 years, $\mathrm{SD}=0.35 ; 26$ boys and 28 girls $), 525$-years-olds $(\mathrm{M}=5.62$ years, $\mathrm{SD}=0.41 ; 22$ boys and 30 girls $)$, and 596 years-olds $(\mathrm{M}=6.52$ years, $\mathrm{SD}=0.37 ; 31$ boys and 28 girls $)$. One-hundred-forty-two $(86 \%)$ of the participants were righthanded. The children were recruited from three kindergartens of Yekaterinburg (the capital of Ural region, The Russian Federation).

All children in this study had a normal birth history and were free of medical, cognitive, language, sensory, and motor impairments in concordance with medical certificate. Children with suspected or known developmental or medical disorders that might affect their performance did not participate in the experiment. Demographic information was not collected systematically, although children appeared to come from a variety of ethnic and socioeconomic backgrounds.

The adult sample comprised 35 persons (17 men and 18 women) between the ages of 19 and 35 ( $M=25.3$ years, $\mathrm{SD}=4.8$ ); these individuals were recruited from students and staff at the Ural State University, The Russian Federation.

\section{Procedure}

All testing was completed in one session, lasting approximately 15 to 20 min with the tests administered in the same order for all participants. The reaction time tasks were presented on IBM PC portable computer with a color monitor (12 in. diameter). Each subject was positioned in front of the computer so that his or her eyes were approximately $40 \mathrm{~cm}$ from the screen. The participants made their responses using keys of standard keyboard of IBM PC computer.

All RT tasks were nonverbal in content, requiring no reading ability. The time between pressing the button and the appearance of the stimulus varied randomly between 500 to $2000 \mathrm{~ms}$. During the trials, a tone was used to signal an incorrect response. The test stimuli consisted of pictures of different animals (3 in diameter).

The test battery consisted of 3 types of reaction time tasks (RT).

\section{The Simple Reaction Time Task (SRT)}

In this task, the participants were required to react as soon as possible by pressing the computer space bar with their dominant hand to a picture of a common bee appearing on the screen. Following administration of 5 practice trials, subject completed 10 experimental trials.

The participant was told, "Look! You see a bee. It will appear on the screen. You will have to push as quickly as possible on the key as soon as the bee appears". 


\section{The Discrimination Reaction Time Tasks}

In this task, the participants were required to react as soon as possible by pressing the computer space bar with their dominant hand to one of two stimuli appearing on the screen. The subject was encouraged to respond as quickly as possible while also maintaining accuracy. Following administration of 5 practice trials, participants completed 20 experimental trials (10 "target" and 10 "non-target"). The subject had to place his/her forefinger of dominant hand on the key, and was asked to keep his/her finger on the key during the task.

The stimulus presentation within a task was randomized across subjects.

This stage consisted of three tasks involving object, color, and orientation discrimination. The general instructions and procedures were the same in all three, but the type of discrimination was varied.

\section{Object Discrimination Reaction (ODR)}

The participant should react as soon as possible to a picture "Tiger" and ignore a picture "Elephant".

The participant was told, "Look! You see a tiger and an elephant. They will appear on the center of screen, sometimes a tiger, sometimes an elephant. You will have to push on the key as soon as possible only when the tiger appears. If you make a mistake, the computer will make a noise. You must answer as quickly as possible, but try to make as few mistakes as possible".

\section{Color Discrimination Reaction $(C D R)$}

The participant should react as soon as possible to a picture of a "Green butterfly" and to ignore a picture of a "Yellow butterfly".

\section{Spatial Discrimination Reaction (SDR)}

The participant should react as soon as possible to a picture of a "Rabbit" and to ignore a mirror image of the same rabbit.

\section{The Choice Reaction Time Tasks}

This stage consisted of 3 blocks involving 2 choice, 2 choice-reversal, and 4 choice responses. Following administration of 5 practice trials, participants completed 20 experimental trials.

\section{Two-Choice Reaction (CR2)}

The participant should react as soon as possible by pushing key the "Left Shift" when a picture of a "Piglet" appeared on the screen and by pushing the "Right Shift" key when a picture of a "Cat" appeared.

The participant was told, "Look! You see a piglet and a cat. They will appear on the center of screen, sometimes a piglet, sometimes a cat. You will have to push this key as soon as possible [examiner pointed to "Left Shift"] only as soon as a piglet appears. You will have to push this key as soon as possible [examiner pointed to "Right Shift"] only as soon as a cat appears. If you make a mistake, the computer will make a noise. You must answer as quickly as possible, but try to make as few mistakes as possible".

The test includes 20 trials (10 "Piglet" and 10 "Cat").

\section{Choice-Reversal Reaction (CRR)}

During this block, participants were instructed to do the opposite of the previous task. That is, they were instructed to press the "Left Shift" key when a picture of a "Cat" appeared and to press the "Right Shift" key when a picture of a "Piglet" appeared.

\section{Four-Choice Reaction (CR4)}

The participant had to respond as quickly as possible to one of four stimuli appearing on the screen by pushing one of four keys.

The participant had to respond to a picture of a "Rabbit" by pushing the "Left Shift", to a picture of a "Turtle" by pushing the key "X", to a picture of a "Lion" by pushing the key ">", and to a picture of a "Bird" by pushing the key "Right Shift". The test included 20 trials (5 "Rabbit", 5 "Turtle", 5 "Lion", and 5 "Bird").

\section{Data Coding}

The mean reaction time of each individual's set of reaction times was calculated for all target detection trials in all RT tasks. Practice trials were not included in the calculation of participant's mean RT. All responses with a response latency exceeding the mean by more than two standard deviations (for each subject and each task, separately) were excluded from the RT analyses (this amounted to less than $2 \%$ of all trials).

\section{RESULTS}

RTs from trials in which accuracy errors occurred were excluded from RT analyses. The Table 1 shows the mean percentage correct in different RT tasks.

As can be seen in Table 1, accuracy rates for all four age groups on the six tasks were quite high.

Table 2 shows means and standard deviations for RT in different RT tasks.

Because the RT data were positively skewed, we computed all statistical tests on the $\log 10$ transformed RT data.

The results per task were evaluated by analyses of variance (ANOVA), with reaction time as dependent variable, with age and gender as between-subjects factors, and the various task manipulations as levels of withinsubject factors in a repeated measurement design.

To examine possible effects of a confounding of sex with group, we initially performed a Group Age $\times$ Sex analysis on RT data from each task. There were no main or interaction effects involving the sex factor. 
Table 1. Mean Percentage Correct on the six RT tasks for the Four Age Groups.

\begin{tabular}{|c|c|c|c|c|c|c|c|c|}
\hline \multirow{2}{*}{$\begin{array}{c}\text { RT } \\
\text { Task }\end{array}$} & \multicolumn{2}{|c|}{ 4-year-old } & \multicolumn{2}{|c|}{ 5-year-old } & \multicolumn{2}{|c|}{ 6-year-old } & \multicolumn{2}{|c|}{ Adult } \\
\hline & $M$ & $S D$ & $M$ & $S D$ & $M$ & $S D$ & $M$ & $S D$ \\
\hline ODR & 97,0 & 3,9 & 95,8 & 4,9 & 94,5 & 4,8 & 97,0 & 4,6 \\
\hline CDR & 95,3 & 6,5 & 98,1 & 3,4 & 97,1 & 3,6 & 98,4 & 2,6 \\
\hline SDR & 93,1 & 7,5 & 96,0 & 4,2 & 97,6 & 3,5 & 98,0 & 4,1 \\
\hline $\mathrm{CR} 2$ & 95,6 & 6,1 & 96,0 & 5,7 & 96,6 & 4,1 & 96,1 & 4,0 \\
\hline CRR & 89,6 & 9,0 & 92,2 & 7,7 & 92,9 & 6,4 & 97,1 & 4,3 \\
\hline CR4 & 88,0 & 13,3 & 92,9 & 11,9 & 95,8 & 5,7 & 95,0 & 8,0 \\
\hline
\end{tabular}

Table 2. Means and Standard Deviations of Reaction Time (in Milliseconds) on the seven RT tasks for the Four Age Groups.

\begin{tabular}{|c|c|c|c|c|c|c|c|c|}
\hline \multirow{2}{*}{$\begin{array}{c}\text { RT } \\
\text { Task }\end{array}$} & \multicolumn{2}{|c|}{ 4-year-old } & \multicolumn{2}{|c|}{ 5-year-old } & \multicolumn{2}{|c|}{ 6-year-old } & \multicolumn{2}{|c|}{ Adult } \\
\hline & $M$ & $S D$ & $M$ & $S D$ & $M$ & $S D$ & $M$ & $S D$ \\
\hline SR & 740 & 162 & 580 & 144 & 467 & 85 & 270 & 31 \\
\hline ODR & 979 & 181 & 804 & 173 & 665 & 104 & 374 & 42 \\
\hline CDR & 1112 & 287 & 900 & 163 & 758 & 111 & 409 & 48 \\
\hline SDR & 1790 & 581 & 1198 & 254 & 949 & 139 & 449 & 51 \\
\hline CR2 & 1145 & 185 & 947 & 160 & 816 & 92 & 469 & 56 \\
\hline CRR & 1472 & 300 & 1161 & 245 & 1022 & 173 & 503 & 66 \\
\hline CR4 & 2485 & 783 & 1652 & 437 & 1346 & 319 & 704 & 132 \\
\hline
\end{tabular}

The analyses were performed twice: one set focusing on the difference between children and adults (age factor with 2 levels: young children and adults), and one set focusing on the child sample (age factor with 3 levels: 4-6 years).

The within-subject factors are: response type (go response in the simple RT task, go/no go response in the discrimination RT task), stimulus type (object, color, and orientation discrimination in ODR, CDR, and SDR correspondingly), reversal of response (CR2 vs. CRR), amount of choices (CR2 vs. CR4).

If we revealed Age Group $\times$ Task Condition interactions we performed ANOVA twice: without transformation and with transformation using approach proposed by Madden et al. [11] and Ridderinkhoff \& van der Molen [3]. Individual RTs are transformed by dividing them on the parameters of the best-fitting regression function (the slowing coefficients of each of the child groups). The transformed RTs are then submitted to ANOVA. We did it to control for the effect of generalized age-related slowing. The assumption of this analysis is that Age Group $\times$ Task Condition interactions that remain significant in analyses of variance of mean RT, following this transformation, can be interpreted as being independent of the generalized slowing represented in the Brinley function.
The slowing coefficients $\left(m_{\text {age }}\right)$ were calculated for each of the three child groups by regressing the mean RTs of the seven tasks for each child group on adult RTs (e.g., the mean RT of 4-year-olds on each of the seven tasks was regressed on the mean RT of adults on the seven tasks). Adult RTs accounted for $85 \%, 93 \%$, and $96 \%$ of the variability of RTs of 4-, 5-, and 6-year-olds, respectively. In addition, the $m_{\text {age }}$ values were found to decrease with age, dropping from 4.07 for 4-year-olds to 2.48 for 5-year-olds, and to 2.06 for 6 year-olds. The relationship of adult RT to that of each of the three child groups is illustrated in Fig. (1), where the mean RT for each of the child groups on each task is plotted against that of adults on the corresponding task.

\section{Age-related Differences between Children and Adults}

\section{ANOVA for Response Types (Simple Reaction vs. Discrimination Reaction)}

The main effect of age was significant, $F(1,199)=$ $313.51, \mathrm{p}<.00001$, indicating that there are age-related differences in RT between children and adults. The main effect of response type was also significant, $F(1,199)=$ 616.02, $\mathrm{p}<.00001$. As expected, RTs were slower in the simple reaction time task ( $g o$ task) than in the discrimination 


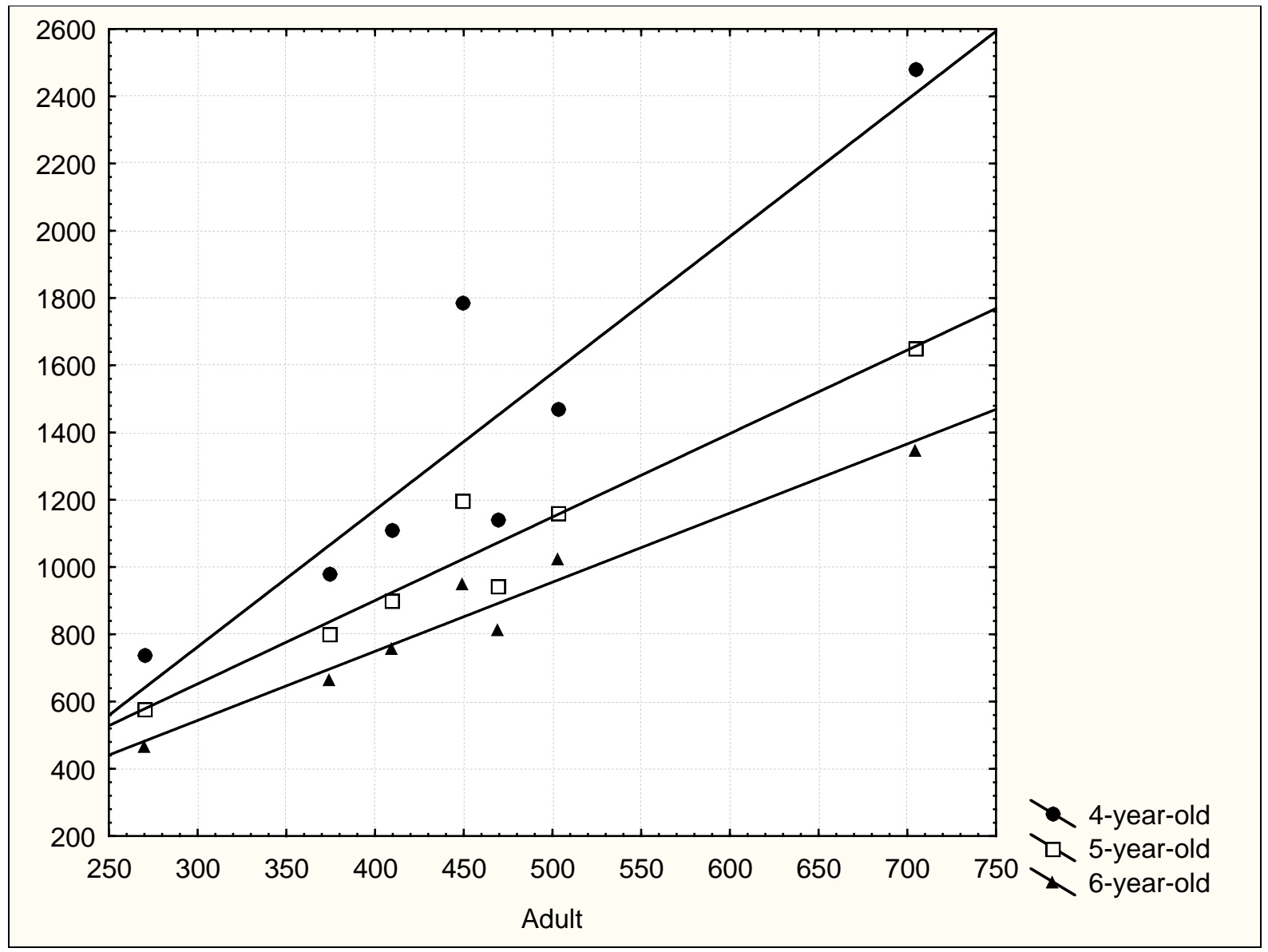

Fig. (1). Linear relationship between adult reaction time and child reaction time for each child group (each slope is fitted to seven data points, representing the seven RT tasks)

RT task (go/no go task). We didn't reveal a significant interaction between response type and age, $F(1,199)=$ $.00015, \mathrm{p}=.99$.

\section{ANOVA for Stimulus Type (Object, Color, Spatial discrimination)}

The main effect of age was significant, $F(1,199)=$ $387.49, \mathrm{p}<.00001$, indicating that there are age-related differences in RT between children and adults. The main effect of stimulus type was also significant, $F(2,398)=$ $162.31, \mathrm{p}<.00001$. RTs were slower in the SDR than in the CDR task, and RTs were slower in the CDR then in the ODR task.

Most interesting, we observed a significant interaction between stimulus type and age, $F(2,402)=31.23, \mathrm{p}<$ .00001 .

When the children's RT data were transformed (using the slowing coefficients), in an ANOVA of the RT data, the original interaction involving age group remained significant, $\mathrm{F}(2,398)=31.07, \mathrm{p}<.00001$, suggesting a process-specific slowing effect.

Additional mixed model ANOVA was conducted to delineate the nature of this interaction. Direct (withinsubject) comparisons between ODR and CDR tasks, and ODR and SDR tasks were carried out.
An ANOVA examined the between-groups factor of age (children and adults), and the within-factors of taskswitching (between object discrimination reaction time task and color discrimination reaction time task, and between object discrimination reaction time task and spatial discrimination reaction time task).

The idea of this comparison was the following. We assume that differences between ODR and CDR reflect the cost of color discrimination processing. Differences between ODR and SDR reflect the cost of orientation discrimination processing. Our interest is to reveal age-related differences in speed of processing color and orientation information.

In comparing RTs in ODR and CDR, main effects of age, $F(1,199)=386.19, \mathrm{p}<.00001$, and stimulus type, $F(1,199)$ $=69.97, \mathrm{p}<.00001$, were observed. But the Stimulus Type Condition $\times$ Age interaction was not significant, $F(1,199)=$ $1.43, \mathrm{p}=.23$.

In comparing RTs in ODR and SDR, there were again main effects of age, $F(1,199)=360.31$, p $<.00001$, and stimulus type, $F(1,199)=249.26$, p $<.00001$.

Most interesting, the Stimulus type $\times$ Age interaction was significant, $F(1,199)=41.62, \mathrm{p}<.00001$, suggesting that although RT increases in spatial discrimination RT task in comparison with object discrimination RT task, this increases was significantly slower for adults. 
When the children's RT data were transformed, in an ANOVA of the RT data, the original interaction involving age group remained significant, $F(1,199)=41.52$, p < .00001 , suggesting a process-specific slowing effect.

\section{ANOVA for Reversal of Response (CR2 vs. CRR)}

The main effect of age was significant, $F(1,199)=$ $455.73, \mathrm{p}<.00001$, indicating that there are age-related differences in RT between children and adults. The main effect for reversal of response was also significant, $F(1,199)$ $=139.74, \mathrm{p}<.00001$. As expected, RTs were slower in the CRR task than in the CR2 task. We revealed a significant interaction between task condition and age, $F(1,201)=$ $36.89, \mathrm{p}<.00001$, suggesting that although RT increases in CRR task in comparison with CR2 task, this increases was significantly slower for adults.

When the children's RT data were transformed, in an ANOVA of the RT data, the original interaction involving age group remained significant, $F(1,199)=35.98, \mathrm{p}<$ .00001 , suggesting a process-specific slowing effect.

\section{ANOVA for Amount of Choices (CR2 vs. CR4)}

The main effect of age was significant, $F(1,199)=$ $304.10, \mathrm{p}<.00001$, indicating that there are age-related differences in RT between children and adults. The main effect for amount of choices was also significant, $F(1,199)=$ $558.88, \mathrm{p}<.00001$. As expected, RTs were slower in the CR4 task than in the CR2 task. We revealed a significant interaction between task condition and age, $F(1,199)=$ $20.36, \mathrm{p}<.00001$, suggesting that although RT increases in CR4 task in comparison with CR2 task, this increases was significantly slower for adults.

When the children's RT data were transformed, in an ANOVA of the RT data, the original interaction involving age group remained significant, $F(1,199)=20.05$, p < .00001 , suggesting a process-specific slowing effect.

\section{Age-related Differences between Children of Three Age Groups}

\section{ANOVA for Response Types (Simple Reaction vs. Discrimination Reaction)}

The main effect of age was significant, $F(2,163)=$ $76.41, \mathrm{p}<.00001$, indicating that there are age-related differences in RT related to age group. The main effect of response type was also significant, $F(2,163)=848.03$, p < .00001 . As expected, RTs were slower in the simple reaction time task (go task) than in the discrimination RT task (go/no go task). We didn't reveal a significant interaction between response type and age, $F(2,163)=3.59, \mathrm{p}=.03$.

\section{ANOVA for Stimulus Type (Object, Color, Spatial discrimination)}

The main effect of age was significant, $F(2,163)=$ $99.13, \mathrm{p}<.00001$, indicating that there are age-related differences in RT related to age group. The main effect of stimulus type was also significant, $F(2,326)=482.84$, p <
.00001. RTs were slower in the SDR than in the CDR task, and RTs were slower in the CDR then in the ODR task.

Most interesting, we observed a significant interaction between stimulus type and age, $F(4,326)=14.07$, p < .00001 .

When the children's RT data were transformed (using the slowing coefficients), in an ANOVA of the RT data, the original interaction involving age group remained significant, $F(4,326)=13.96, \mathrm{p}<.00001$, suggesting a process-specific slowing effect.

Additional mixed model ANOVA was conducted to delineate the nature of this interaction. Direct (withinsubject) comparisons between ODR and CDR tasks, and ODR and SDR tasks were carried out.

In comparing RTs in ODR and CDR, main effects of age, $F(2,163)=71.78, \mathrm{p}<.00001$, and stimulus type, $F(2,163)=$ $112.47, \mathrm{p}<.00001$, were observed. But the Stimulus Type Condition $\times$ Age interaction was not significant, $F(2,163)=$ $0.20, \mathrm{p}=, 82$.

In comparing RTs in ODR and SDR, there were again main effects of age, $F(2,163)=104.49, \mathrm{p}<.00001$, and stimulus type, $F(2,163)=724.13, \mathrm{p}<.00001$. Most interesting, the Stimulus type $\times$ Age interaction was significant, $F(2,163)=16.21, \mathrm{p}<.00001$, suggesting that although RT increases in spatial discrimination RT task in comparison with object discrimination RT task, this increases was significantly slower for older children.

When the children's RT data were transformed, in an ANOVA of the RT data, the original interaction involving age group remained significant, $F(2,163)=15.95$, $\mathrm{p}<$ .00001 , suggesting a process-specific slowing effect.

\section{ANOVA for Reversal of Response (CR2 vs. CRR)}

The main effect of age was significant, $F(2,163)=70.73$, $\mathrm{p}<.00001$, indicating that there are age-related differences in RT between children and adults. The main effect for reversal of response was also significant, $F(2,163)=422.52$, $\mathrm{p}<.00001$. As expected, RTs were slower in the CRR task than in the CR2 task. We didn't reveal a significant interaction between task condition and age, $F(2,163)=1.43$, $\mathrm{p}<.24$.

\section{ANOVA for Amount of Choices (CR2 vs. CR4)}

The main effect of age was significant, $F(2,163)=91.38$, $p<.00001$, indicating that there are age-related differences in RT between children and adults. The main effect for amount of choices was also significant, $F(2,163)=1287.8, \mathrm{p}$ $<.00001$. As expected, RTs were slower in the CR4 task than in the CR2 task. We revealed a significant interaction between task condition and age, $F(2,163)=23.44$, p < .00001 , suggesting that although RT increases in CR4 task in comparison with CR2 task, this increases was significantly slower for older children.

When the children's RT data were transformed, in an ANOVA of the RT data, the original interaction involving age group remained significant, $F(2,163)=23.82 \mathrm{p}<.00001$, suggesting a process-specific slowing effect. 


\section{DISCUSSION}

This research demonstrate that there are clear age-related differences in processing speed not only between young children and adults but also between three age groups of young children.

The use of the regression approach in this study provides further support for the presence of the global age-related differences in processing speed both between young children and adults and between young children of three age groups. The current data also confirmed the results of previous researches that the magnitude of the slowing coefficient decreases with increasing age $[8,13,14]$.

However, using transformation method proposed be Madden et al. [11] and Ridderinkhoff \& van der Molen [3] we revealed that there are not only global age-related differences but also process-specific age-related differences in processing speed. In particular, in comparing children and adults the age-related differences in the spatial discrimination (SDR), choice-reversal (CRR), and fourchoice (CR4) reaction time tasks were larger than predicted by the global-difference hypothesis. In comparing young children of three age groups the age-related differences in SDR and CR4 also were larger than predicted by the globaldifference hypothesis.

We assume that the obtained results can be explained by the idea that there are different sources of slowing, some of which is general and some of which may be related to taskspecific demands.

On the one hand, it is plausible that there is some global developmental mechanism that influences the reducing reaction time during child development. It can be so-called "General Speed Factor" that is usually extracted from a covariance matrix using factor analytic techniques in the researches of individual differences. We use this term in accordance with idea of Jensen [15], who stated that "in several multivariate studies [of response latency] ... that I have seen, however, one feature is quite clear: There is always a large General Speed factor along with other relatively smaller factors associated with particular processes" (p.120). The use of the regression analysis in the developmental researchers gives some evidences for assumption that there are also clear age-related differences in General Speed Factor $[4,16]$. This idea has received irresistible support by the outcomes of empirical and metaanalytical studies $[1,13,16]$.

However, general slowing is not sufficient to explain the full range of age-related differences in processing speed reported in literature [17]; some component processes may be affected more by age than others $[18,19]$. In other words, it is plausible that there are some task-specific mechanisms that also influence the reducing reaction time during child development.

This idea can be easily accepted in view of recent conceptions about brain development, in particular, conception about heterochronicity of human brain development [20-22]. The heterochronicity means that different brain areas follow temporally distinct maturational trajectories. For example, it was shown that higher-order association areas, such as the prefrontal and lateral temporal cortices, mature only after the lower-order somatosensory and visual cortices have matured [20,22]. In other words, it seems plausible that the regions associated with more primary functions, such as motor and sensory systems, develop earlier compared with the regions that are involved with more complex and integrative functions such as basic language skills, spatial orientation, and executive functions [20].

We assume that the age-related differences in processing speed can be understood in relation to the heterochronicity of child brain development. This approach predicts that agerelated differences in RT tasks involving less developed brain areas in children should be more pronounced than age differences in RT tasks involving mature brain areas. In other words, if RT task involves those brain areas that are in the condition of intensive maturation in this period of child development then we can predict more pronounced agerelated differences in this RT task between children of these ages. In this case not only General Speed Factor contributes in the age-related differences in RT task but also the specific mechanisms that are related to these intensive maturing brain areas.

In the current research, we used the spectrum of RT tasks that vary in the demand on perceptual, visuospatial and executive functions. In particular, the spatial discrimination reaction time task (SDR) involves relatively more visuospatial abilities then object discrimination reaction time task (ODR); the color discrimination reaction time task (CDR) involves relatively more the processing color information then object discrimination reaction time task (ODR). The processing color information is closely related to the occipital sensory cortex, whereas the processing orientation information is closely related to the lateral temporo-occipital cortex [23]. It was shown that the occipital sensory cortex matures earlier than the lateral temporooccipital cortex $[20,21]$. Moreover, by the age of 4 the efficiency of color processing seems to have reached mature levels of performance [24]. In other words, it seems that there aren't the age-related differences in color processing information between children of 4, 5, and 6 years of age. In opposite, in view of intense maturation of the lateral temporo-occipital cortex in this period of child development $[20,21,25]$ we can expect pronounced age-related differentces in spatial processing information between children of these age groups. These evidences can help us to explain the results obtained in this study concerning age-differences in various discrimination reaction time tasks.

We revealed that age-related differences between three child groups in SDR tasks are more pronounced than in CDR tasks. We assume that the demands on visuospatial functions that are related to less developed temporo-occipital cortex affect the speed of responding in spatial discrimination reaction time task over and above global-speed effects. In opposite, the demands on color processing function that is related to mature visual cortex do not affect the speed of 
responding in color discrimination reaction time task over and above global-speed effects. In other words, the agerelated differences in the CDR task can be explained in terms of a single, global mechanism.

As regards the reaction time tasks involving executive functions, we obtained quite discrepant results. We suggest that executive functions play a more prominent role in object discrimination reaction time task (ODR) relative to simple reaction time task (SR), and in the choice-reversal reaction time task (CRR) and four-choice reaction time task (CR4) relative to two-choice reaction time task (CR2). In view of pronounced age-related differences in executive functions between children and adults and intense maturation of the brain mechanisms involved in executive function in children $[20,26,27]$ we expected the presence of the Age Group $\times$ Task Condition interaction in comparing SR with ODR, and in comparing CR2 with CRR and CR4. However, we obtained this expected results only for CRR and CR4 in comparing children and adults, and for CR4 in comparing children of three age groups.

One possibility to consider is that both global processing speed and executive function contribute to the effects of advancing age on the efficiency of reaction time performance only in case of high load on executive functions. We assume that the load on executive functions is more in CRR and CR4 tasks relative to CR2 task then in ODR relative to SR task.

The absence of the Age Group $\times$ Task Condition interaction in comparing CR2 with CRR in three age groups can be explained by the assumption that in this period of child development there is not the pronounced age-related difference in ability that is involved in performance of the choice-reversal reaction time task (CRR). In this case, the age-related differences in the CRR task between three age groups can be explained possibly in terms of a single, global mechanism.

It is necessary to note that the order of stimulus presentation was not varied in this study. So it is possible that practice effect and order of presentation effect due to lack of counterbalancing could influence to a certain extent the obtained results. This point leads us to necessity to check out the obtained results using the counterbalanced design of reaction time tasks. Besides, we plan to focus on more specific components of reaction time performance with more attention to visuospatial domain. It is related to the relative lack of information about the development of visuospatial processing information in comparison with research in the area of executive functions.

In conclusion, the obtained results give some evidences that global mechanism can't account for the full range of age-related differences in the processing speed in young children, and that there are the process-specific differences in processing speed which can be possible explained by the heterochronicity of human brain development.

\section{CONFLICT OF INTEREST}

The authors confirm that this article content has no conflicts of interest.

\section{ACKNOWLEDGEMENTS}

This research was supported by a grant from the Russian Humanitarian Science Foundation №12-06-00616. The authors thank the child and adult participants from the Russian Federation.

\section{REFERENCES}

[1] Hale S. A global developmental trend in cognitive processing speed. Child Develop 1990; 61: 653-63.

[2] Kail R. Developmental functions for speeds of cognitive processes. J Exp Child Psychol 1988; 45: 339-64.

[3] Ridderinkhof K, van der Molen M. Mental resources, processing speed, and inhibitory control: A developmental perspective. Biol Psychol 1997; 45: 241-61.

[4] Cerella J, Hale S. The rise and fall in information-processing rates over the life span. Acta Psychol 1994; 86: 109-97.

[5] Kail R. The role of a global mechanism in developmental change in speed of processing. In: Howe M, Pasnak R, Eds. Emerging themes in cognitive development. New York: Springer-Verlag 1993; vol. 1: pp. 97-116.

[6] Brinley J. Cognitive sets, speed, and accuracy of performance in the elderly. In: Welford A, Birren J, Eds. Behavior, aging, and the nervous system, IL, Springfield 1965: pp. 114-49.

[7] Bashore T, Smulders F. Do general slowing functions mask local slowing effects? A chronopsychophysiological perspective. In: Allen P, Bashore T, Eds. Age differences in word and language processing, Amsterdam: North Holland, 1995: pp. 390-426.

[8] Miller L, Vernon P. Developmental changes in speed of information processing in young children. Develop Psychol 1997; 33: 549-54.

[9] Dempster F. Resistance to interference: Developmental changes in a basic processing dimension. In: Howe M, Pasnak R, Eds. Emerging themes in cognitive development. New York: SpringerVerlag 1993; vol. 1: pp. 3-27.

[10] Bashore T. Some thoughts on neurocognitive slowing. Acta Psychol 1994; 86: 295-325.

[11] Madden D, Pierce T, Allen P. Adult age differences in attentional allocation during memory search. Psychol Aging 1992; 7: 594-601.

[12] Madden D. Speed and timing of behavioral processes. In: Birren J, Schaie K, Eds. Handbook of the psychology of aging. Academic Press: San Diego, 2001; 5th ed.: pp. 288-312.

[13] Kail R. Developmental changes in speed of processing during childhood and adolescence. Psychol Bull 1991; 109: 490-501.

[14] Kail R, Park Y. Global developmental change in processing time. Merrill-Palmer Quart 1992; 38: 525-41.

[15] Jensen A. Speed of information processing and population differences. In: Irvine S, Berry J, Eds. Human abilities in cultural context, Cambridge, England: Cambridge University Press 1988: pp. $105-45$.

[16] Kail R, Salthouse T. Processing speed as a mental capacity. Acta Psychol 1994; 86: 199-225.

[17] Fisk A, Fisher D. Brinley plots and theories of aging: The explicit, muddled, and implicit debates. J Gerontol 1994; 49: 81-9.

[18] Fisk A, Fisher D, Rogers W. General slowing alone cannot explain age-related search effects: A reply to Cerella. J Exp Psychol 1992; 121: 73-8.

[19] Madden D, Pierce T, Allen P. Age-related slowing and the time course of semantic priming in visual word identification. Psychol Aging 1993; 8: 490-507.

[20] Casey B, Tottenham N, Liston C, Durston S. Imaging the developing brain: What have we learned about cognitive development? Trends Cognit Sci 2005; 9: 104-10.

[21] Farber D. Principles of structural and functional brain organization in ontogenesis: Main stages of its formation. In: Farber D, Njiokikjien C, Eds. Pediatric neurology. Developing brain and cognition. Suyi, Amsterdam 1993; vol. 4: pp. 156-168.

[22] Gogtay N, Giedd J, Lusk L, et al. Dynamic mapping of human cortical development during childhood through early adulthood. Proc Natl Acad Sci USA 2004; 101: 8174-9.

[23] Luria A. Higher Cortical Functions in Man. Basic Books: New York 1966. 
[24] Brown A. Development of visual sensitivity to light and color vision in human infants: A critical review. Visual Res 1990; 30: 1159-88.

[25] Stiles J, Bates E, Thal D, Trauner D, Reilly J. Linguistic and spatial cognitive development in children with pre- and perinatal focal brain injury: A ten-year overview from the San Diego Longitudinal Project. In: Johnson M, Munakata Y, Gilmore R, Eds. Brain development and cognition: A reader, $2^{\text {nd }}$ ed.: Blackwell, Oxford, UK, 2002; pp. 272-91

[26] Welsh M, Pennington B, Groisser D. A normative-developmental study of executive function: A window on prefrontal function in children. Develop Neuropsychol 1991; 7 : 131-49.

[27] Zelazo P Mueller U. Executive function in typical and atypical development. In: Goswami U, Ed. Handbook of childhood cognitive development, Oxford, UK: Blackwell. 2002: pp. 445-69.

Received: January 02, 2014

Revised: August 12, 2014

Accepted: October 15, 2014

(C) Sergey Kiselev; Licensee Bentham Open.

This is an open access article licensed under the terms of the Creative Commons Attribution Non-Commercial License (http://creativecommons.org/licenses/bync/3.0/), which permits unrestricted, non-commercial use, distribution and reproduction in any medium, provided the work is properly cited. 